\title{
ABSENTISMO ESCOLAR EN ESPAÑA. DATOS Y REFLEXIONES ${ }^{1}$
}

\author{
José Ignacio Cruz Orozco
}

Universitat de València

RESUMEN: El absentismo escolar no recibe en España la atención que merece. Pese a que diversos estudios señalan que la ausencia de las aulas del alumnado en edad de escolarización obligatoria es más amplia de lo que parece -los informes PISA, por ejemplo, lo cuantifican entre el 25 y el $28 \%$ del alumnado de $4^{\circ}$ de la secundaria obligatoria- esta realidad presenta una escasa visibilidad educativa y social. En el trabajo se realiza una primera clarificación conceptual del problema, para posteriormente analizar con un enfoque integral la normativa legal que articula en nuestro país: el derecho a la educación; la escolarización obligatoria y el absentismo. A partir de ese marco teórico, se señalan los trabajos que evidencian la destacada incidencia de las conductas absentistas. Por último, se constata la significativa diferencia entre lo planteado en la normativa vigente y la incidencia del alumnado absentista, según los citados estudios. En base a lo anterior, se plantea la necesidad de una mayor intervención por parte de las autoridades educativas para una más eficaz aplicación del derecho a la educación, que de acuerdo con nuestro ordenamiento tiene el carácter de derecho fundamental.

PALABRAS CLAVE: absentismo escolar, derecho a la educación, escolaridad obligatoria, políticas educativas.

\section{SCHOOL ABSENTEEISM IN SPAIN. DATA AND REFLECTIONS}

ABSTRACT: School absenteeism is not paid the attention it deserves in Spain. Despite several studies demonstrating that more pupils of compulsory education ages do not go to school than is apparently assumed -for example, PISA reports quantifying between $25 \%$ and $28 \%$ of year-4 Compulsory Secondary Education students-, this socio-educational reality is scarcely visible. The present work offers an initial conceptual clarification of the

1. Este trabajo ha contado con la ayuda del proyecto UV-INV-AE18-784553 de la Universitat de València. 
problem before applying an integral approach to analyse the legal regulations in force in our country: the right to education; compulsory schooling and absenteeism. According to this theoretical framework, works that have evidenced the accentuated incidence of absenteeism conducts are shown. Finally, the significant difference between what current regulations set out and the incidence of absentee students is confirmed according to the cited studies. Based on all this, the need for greater intervention by education authorities is considered to more efficiently apply the right to education which, according to Spanish regulations, is a fundamental right.

KEYWORDS: School absenteeism, right to education, compulsory schooling, education policies.

Recibido: 05/12/2019

Aceptado: 04/02/2020

Correspondencia: José Ignacio Cruz Orozco. Universidad de Valencia, Facultad de Educación, Avda. de Blasco Ibáñez, 30, 46010 Valencia. Email: jose.i.cruz@uv.es.

\section{INTRODUCCIÓN}

El actual sistema educativo español tiene establecido un tramo de escolarización obligatoria de diez cursos que comprende la Educación Primaria, entre los 6 y los 11 años, y la Educación Secundaria Obligatoria (ESO) desde los 12 a los 16 años. Esa configuración se estableció hace casi tres décadas, en 1990, con la Ley Orgánica General del Sistema Educativo (LOGSE). Pese al permanente debate al que está sometida la política de la educación en nuestro país y la alternancia de gobiernos de distinto signo, ese elemento estructural de la arquitectura de las enseñanzas no universitarias no ha sufrido modificaciones sustantivas desde su implantación.

Con dicha norma se culminó un amplio proceso iniciado con la configuración del sistema educativo nacional en las primeras décadas del siglo XIX, una de cuyas finalidades fundamentales consistió en vertebrar e implantar el derecho a la educación entre las nuevas generaciones. Al respecto deben señalarse, por citar los ejemplos más cercanos cronológicamente, las iniciativas que la administración educativa realizó desde mediados del siglo XX, por medio de una serie de destacadas iniciativas normativas y de intervención. Desde mediados de la década de 1950, la política educativa tuvo una inequívoca orientación estatista, y se fue concretando en potentes actuaciones en forma de creación de infraestructuras materiales, dotación de recursos personales, así como en la conformación de una sólida arquitectura legal, de la que fue un buen exponente la Ley General de Educación (LGE) de 1970. Todas ellas, desde el enfoque que estamos empleando y pese a su dispar orientación pedagógica e ideológica, deben considerarse en gran medida como antecedentes destacados de la reforma culminada en 1990 con la LOGSE, y su huella aún se deja sentir en el actual panorama educativo español (Viñao, 2004; Cruz, 2019). 
Una vez que, a partir de esta última ley, quedó fijada la estructura de las enseñanzas no universitarias, el interés de la política educativa, tanto desde el enfoque más técnico, profesional y académico, como desde la perspectiva más centrada en la opinión pública y en los intereses políticos, se desplazó a las cuestiones relacionadas con la calidad de la educación, dando por superada una larga etapa en que el principal objetivo había consistido en atender a las familias que demandaban un puesto escolar en condiciones para los niños y jóvenes en edad de escolarización obligatoria (Calero, Choi y Waisgrais, 2010; Rodríguez, Fernández y Jover, 2017 y Asensio, Carpintero, Expósito y López, 2018).

Dentro de ese contexto, pareció darse por supuesto que ese gran objetivo, perseguido desde que se inició la configuración del sistema educativo nacional, se había alcanzado finalmente, y que todos los chicos y chicas españoles comprendidos entre los 6 y 16 años acudían a las aulas con regularidad. El problema de la falta de escolarización y la ausencia del alumnado a las aulas, esto el absentismo escolar, fue desapareciendo de las demandas y los debates sobre la política educativa, y también se restringió notablemente el interés académico por ese problema.

La cuestión a la que quiere dar respuesta este trabajo parte de esta reflexión ya esbozada, pero que aquí explicitamos con mayor detalle, desgranándola en las siguientes preguntas. ¿El amplio conjunto de medidas señalado con la finalidad de consolidar la escolarización, ha conseguido erradicar el problema del absentismo escolar? ¿Hasta qué punto se han reducido las ausencias injustificadas a las aulas entre el alumnado en edad de escolarización obligatoria? ¿La ausencia de referencias a ese problema en la agenda pública sobre política de la educación y en la investigación académica, se encuentra motivada por notable reducción de la incidencia de ese tipo de situaciones?

Una serie de tenues, pero bien fundadas, referencias -académicas, sociales y educativas- nos indican que, a pesar de su escasa visibilidad, el absentismo escolar continúa estando presente en la realidad educativa, y, en más casos de los que pareciera, con una significativa incidencia. Este trabajo se va a centrar en responder a las preguntas anteriores, aportando referencias para dimensionar el problema del absentismo desde un enfoque global, sin entrar en el estudio de sus causas y otros aspectos de gran importancia, pero que necesitarían un espacio mucho mayor del que disponemos.

\section{Precisiones conceptuales}

Llegados a este punto, parece oportuno dedicar un breve apartado a realizar algunas precisiones conceptuales que permitan clarificar y concretar el sentido de nuestro trabajo. En ocasiones, se emplean los términos absentismo escolar, abandono escolar temprano y fracaso escolar, para describir realidades parecidas, e, incluso, se llega a considerar como conceptos similares. Resulta evidente de que todos ellos se encuentran relacionados, pero en sentido estricto, que es como los empleamos en este trabajo, se trata de categorías plenamente diferenciadas. 
En la actualidad, el abandono escolar temprano o prematuro es un concepto con amplia presencia y común reconocimiento, el cual se toma como un importante indicador de la calidad un sistema educativo, sobre todo dentro de la Unión Europea. En concreto, se conceptualiza del modo siguiente:

Eurostat define el abandono escolar prematuro (early school leaving) como "The percentage of population aged 18-24 with at most lower secondary education a not in further education or training." En España, el lower secondary level (nivel CINE-2 de la UNESCO) se corresponde con la etapa de la Educación Secundaria Obligatoria y el Upper secondary level se corresponde con el Bachillerato (nivel CINE-3A) y los Ciclos formativos de Grado Medio (nivel CINE- 3B). (Faci, 2011, 1)

Este autor señaló, en su momento, que en el sistema educativo español el abandono escolar temprano corresponde al porcentaje del alumnado de entre 18 y 24 años de edad que solo cuenta con un nivel de estudios básico, hasta el último curso de la escolarización obligatoria que corresponde con el $4^{\circ}$ de la ESO.

Por su parte, Escudero y Rodríguez, reconocidos especialistas en la materia, apuntan por su parte que: "El abandono escolar temprano en el sistema educativo español está siendo un tema recurrente de análisis y propuestas, especialmente en la última década" $(2011,1)$. A lo que podemos añadir que como ha sido intensamente impulsado desde la Unión Europea, goza de destacada visibilidad social y académica y que su gran concreción cuantitativa facilita el empleo frecuente en informes y estudios.

En lo que respecta al absentismo escolar, de acuerdo con el criterio unánime de los especialistas, se define como la inasistencia injustificada a las aulas de un menor en edad de escolarización obligatoria, que en el caso español se circunscribe a los niños y niñas de entre 6 y 16 años (González, 2006; García Gracia 2013; Cruz, García y Grau, 2017).

Al respecto, cabría realizar una par de consideraciones para clarificar algunas confusiones. El absentismo se centra exclusivamente en alumnado que se encuentra en edad de escolarización obligatoria, cursando las enseñanzas correspondientes. Por el contrario, el abandono escolar temprano se refiere siempre, de acuerdo con su propia definición, a jóvenes que no prosiguen estudios tras el periodo obligatorio. Mientras el primero guarda relación directa con el derecho a la educación, o con mayor precisión, con el incumplimiento de este derecho, el abandono escolar no se sitúa en el territorio de los derechos y deberes, si no que se ubica fuera de él. Un joven en situación de abandono escolar, no está incumpliendo ningún deber, ni se encuentra privado del disfrute de ningún derecho. Su situación se ubica en un ámbito sensiblemente distinto, tomándose como referente del potencial económico de un estado.

Por su parte están claras a simple vista las vinculaciones entre ambos conceptos y el fracaso escolar. Con bastante mayor intensidad en el caso del absentismo, ya que la ausencia injustificada de las clases Ileva casi indefectiblemente a la imposibilidad de la certificación de los estudios. En España se concreta en casi todas las ocasiones en la exclusión del Título de Graduado en la Educación Secundaria Obligatoria, lo que 
significa un serio obstáculo para el acceso a la mayoría de los puestos de trabajo con cierta especialización, que por norma general suelen ser los mejor regulados y remunerados. Este último aspecto también podemos aplicarlos a los jóvenes en situación de abandono escolar temprano, aunque atemperada en el caso de los que cuentan con la correspondiente certificación.

\section{Marco normativo}

Una vez aclarado lo que entendemos por absentismo escolar y los puntos de contacto y las diferencias existentes con las categorías de rechazo escolar y abandono temprano, debemos cambiar de perspectiva. El siguiente paso que vamos a realizar nos lleva a analizar cómo se contempla desde el punto de vista de la normativa legal. Debemos partir de una premisa lógica: el absentismo supone la vulneración el incumplimiento de una obligación, en concreto el incumplimiento del derecho a la educación de unos chicos y chicas menores de edad que se encuentran en el periodo de escolarización obligatoria. Por tanto, debemos ver cómo está contemplado el derecho a la educación en la legislación española.

La Constitución española aprobada en 1978, que regula nuestro actual sistema de ordenamiento político, señala en el artículo 27.4 lo siguiente: "La enseñanza básica es obligatoria y gratuita" (CE, 1978) En ese aspecto, como en otros, la carta magna incorporó una doctrina política y jurídica de carácter internacional con amplios antecedentes y que tuvo uno de sus hitos más destacados en la Declaración Universal de los Derechos Humanos (Asamblea General de la ONU, 1948). En ella se situó el derecho a la educación entre los derechos fundamentales de las personas. Como es conocido, en su artículo 26 se puede leer que "toda persona tiene derecho a la educación", planteamiento que las Naciones Unidas han ido ratificando en todas las Convenciones y Pactos que han ido aprobando desde 1948 para desarrollar los principios enunciados en la Declaración Universal.

Así ocurre en la Convención sobre los Derechos del Niño de 1959, principio 7, en el Pacto Internacional de Derechos Civiles y Políticos de 1966, artículo 24, en el Pacto Internacional de los Derechos Económicos, Sociales y Culturales de 1966, artículo 13.2, y en la Convención sobre los Derechos del Niño de 1989, artículo 28. Desde el marco estrictamente europeo, y teniendo en cuenta la integración de España en la Unión Europea, hay que señalar que el Convenio Europeo de Derechos Humanos, Protocolo adicional al Convenio para la Protección de los Derechos Humanos y de las Libertades Fundamentales de 1952, artículo 2, y la Carta Europea de los Derechos del Niño de 1992, también insisten en resaltar la importancia del derecho a la educación para niños y niñas (Cruz, García y Grau, 2016).

Por otra parte, el planteamiento que efectúa la Constitución con respecto al derecho a la educación, se ha ido concretando en las sucesivas leyes orgánicas que han regulado la política educativa. Hoy en día está vigente la Ley orgánica de Mejora de la Calidad Educativa (LOMCE), la cual señala en su artículo 3.3 que: "La educación primaria y la educación secundaria obligatoria constituyen la enseñanza básica". Lo cual es completado en el artículo 4 donde se indica: "La enseñanza básica a que se 
refiere el artículo 3.3 de esta Ley es obligatoria y gratuita para todas las personas" (LOMCE, 8/2013). Debe añadirse que este aspecto concreto no ha variado de formulación, dentro del intenso proceso de modificación de la arquitectura normativa de la enseñanza no universitaria que se ha llevado a cabo en las últimas tres décadas.

Otra cuestión que debe tenerse en cuenta es que el derecho a la educación, no se ha enfocado exclusivamente desde la perspectiva de la política de la educación. También, la doctrina y la normativa que tienen como objeto la protección del menor en situaciones de riesgo y desprotección, han tenido muy en cuenta la escolarización y, en consecuencia, le ha otorgado una destacada importancia en la legislación correspondiente. Así, la Ley Orgánica 1/1996 de Protección Jurídica del Menor,ㄹ que regula todo lo relativo a la situación de los menores que se encuentran en situación de desprotección por la razón que fuere, indica en su artículo 13, apartados 2 y 3 lo siguiente:

2. Cualquier persona o autoridad que tenga conocimiento de que un menor no está escolarizado o no asiste al centro escolar de forma habitual y sin justificación, durante el período obligatorio, deberá ponerlo en conocimiento de las autoridades públicas competentes, que adoptarán las medidas necesarias para su escolarización.

3. Las autoridades y las personas que por su profesión o función conozcan el caso actuarán con la debida reserva. (LOPJM, 1/1996)

Este claro planteamiento sobre cómo las autoridades de todo tipo deben afrontar el absentismo, lo encontramos reproducido en las leyes autonómicas que se han ido aprobando, a partir de la norma anterior que tiene carácter de normativa-marco. Como ejemplo podemos citar la Ley 26/2018, de 21 de diciembre, de la Generalitat Valenciana, de derechos y garantías de la Infancia y la adolescencia.

En el artículo 49, titulado específicamente No escolarización, absentismo y abandono escolar, se señala, en primer término, que los padres y tutores legales deben responsabilizarse de "que las personas menores de edad... cursen de manera real y efectiva los niveles obligatorios de enseñanza, y de garantizar su asistencia a clase". Lo cual se complementa con el compromiso del, gobierno autonómico de la Comunidad Valenciana, para "coordinar y emprender las acciones necesarias para el cumplimiento de la escolaridad obligatoria, de acuerdo con la legislación vigente y evitar el absentismo y abandono escolar" (LGDGIA 26/2018).

Como se puede comprobar, la normativa sobre el absentismo escolar presenta unas características comunes. En primer término, como se deduce de las citas de los párrafos precedentes, es amplia y afronta esta problemática desde diferentes perspectivas, lo que denota un serio interés político y social. A continuación, debe situarse que, pese a la variedad de normas, no existe ninguna duda a la hora de concebir e in-

2. Esta ley fue actualizada por la Ley $26 / 2015$, de 28 de julio, de modificación del sistema de protección a la infancia y a la adolescencia. Mantenemos la anterior referencia ya que los cambios se centraron en otros aspectos, y se mantuvo por completo el articulado al que hacemos referencia. Para la ley 26/2015 https://www.boe.es/buscar/pdf/2015/BOE-A-2015-8470-consolidado.pdf consultada el 10 de octubre de 2019. 
terpretar el contenido del derecho a la educación. Se considera uno de los derechos fundamentales, y en lo que se refiere a los niveles obligatorios, no estima aceptable ningún argumento para disculpar la asistencia de los menores a los centros, a no ser que sea por causa de fuerza mayor.

Igualmente, la legislación centrada en la protección del menor, al dirigirse a una población en situación de riesgo o desprotección, detalla más explícitamente los objetivos y medidas a tomar. En concreto, especifica, entre otros aspectos, que incumbe a cualquier tipo de autoridad: educativa, local, autonómica, policial, etc. Pero no solo eso, la Ley 1/1996, de ámbito estatal, indica que cualquier persona debe denunciar ante las autoridades competentes los casos de absentismo de los que tenga conocimiento. Se considera, por tanto, que es un asunto que compete a la sociedad en su conjunto (LOPLM, 1/1996).

El repaso que estamos realizando a la normativa sobre el absentismo escolar, tiene que incluir un par de elementos más, con rasgos muy diferentes a los que hemos analizado hasta el momento, y que guardan relación con las competencias y responsabilidades ante las situaciones de absentismo. En primer término, debemos referirnos a las corporaciones locales, las cuales tienen atribuidas, entre los asuntos que le son propios, la escolarización de los niños y niñas de su población, tal como queda dispuesto en el artículo 25 de la ley de racionalización y sostenibilidad de la Administración local actualmente en vigor (LRSAL, 27/2013).

Y en último lugar debemos indicar que el Código Penal actual en vigor, también contempla el problema del absentismo, aunque de una manera indirecta. En concreto, en el artículo 226 que reproducimos a continuación:

El que dejare de cumplir los deberes legales de asistencia inherentes a la patria potestad, tutela, guarda o acogimiento familiar o de prestar la asistencia necesaria legalmente establecida para el sustento de sus descendientes, ascendientes o cónyuge, que se hallen necesitados, será castigado con la pena de prisión de tres a seis meses o multa de seis a 12 meses. (LOCP, 10/1995)

En España el consentimiento del absentismo escolar por parte de los padres o tutores legales está incluido dentro del delito denominado abandono de familia. Esto significa que ante una denuncia, si se comprueba por parte de la Fiscalía de Menores correspondiente algunas circunstancias -reiteración e intencionalidad, entre otras-, los padres pueden ser acusados por tal delito, ser llevados ante un tribunal y, en su caso, ser condenados a penas de prisión.

De acuerdo con toda la normativa descrita, cuando se detectan casos de absentismo escolar las autoridades deben poner en marcha unos planes de intervención. Como se ha ido apuntando, existen diversas entidades que deben velar por el correcto cumplimiento de la aplicación del derecho a la educación, ya que se trata de una competencia compartida. En primer término, todo centro docente debe responsabilizarse del alumnado que se encuentra matriculado en el mismo. Diariamente el profesorado está obligado a pasar lista y anotar las faltas, indicando si están justificadas o no. Cuando se detecta un alumno en edad de escolarización obligatoria que presenta una conducta absentista, el centro, mediante los mecanismos que 
tenga establecidos -normalmente a través del tutor, los servicios psicopedagógicos y el responsable del programa de absentismo si lo hubiera-, debe ponerse en contacto con él y con su familia e intentar que el alumno se reincorpore a las clases (García Gracia, 2013).

Si la situación no se reconduce, y teniendo en cuenta que el ámbito de actuación del profesorado se encuentra estrictamente limitada a los recintos escolares,.el centro está obligado a poner los hechos en conocimiento de los Servicios Sociales y la Comisión Municipal de Absentismo del ayuntamiento correspondiente. Desde allí se activarán los programas de intervención social previstos, que por norma general consisten en una serie de actuaciones sobre la familia y el propio menor.

Si este protocolo de intervención tampoco tiene éxito, las faltas de asistencia persisten y se deduce que las familias no han actuado para solucionar las causas, los servicios municipales deben informar a la Fiscalía de Menores, la cual, tras valorar la situación y realizar las oportunas averiguaciones, puede abrir un expediente de Diligencias de Investigación Penal (D.I.P.) a las personas encargadas de la tutela del menor por un posible delito de abandono de familia. Este expediente puede acabar ante un Juzgado de lo Penal y, en su caso, los acusados pueden ser condenados a penas de cárcel (Cruz, García y Grau, 2017).

\section{Cuantificación}

Como ya se indicó anteriormente, la consolidación de nuestro sistema educativo, la ampliación de la escolarización obligatoria hasta los 16 años y el protagonismo de las cuestiones vinculadas a la calidad de la educación, han supuesto que el absentismo desapareciera de la agenda de la política educativa. También dejaron de publicarse los registros sobre ese tipo de conductas, por los que todos los especialistas que han trabajo este problema, lamentan unánimemente la ausencia de datos fiables. (Bueno, 2005; González, 2006).

Se da una circunstancia paradójica, como se podrá comprobar con mucha claridad en las páginas siguientes. Mientras las referencias al absentismo han desaparecido de las estadísticas educativas oficiales, los claustros y equipos directivos de algunos centros y los técnicos y responsables de ciertos servicios municipales, manifiestan una creciente preocupación por el abundante número de alumnos que se ausenta injustificadamente de las aulas. Esto nos marca otra de las características del problema: su invisibilidad y falta de presencia pública. Por un lado, existe una seria preocupación en sectores del profesorado, desde una perspectiva de micro política, pero esta apenas cuenta con reflejo en las esferas de decisión, en el ámbito de la macro política educativa.

Centrándonos en la dimensión cuantitativa de este problema, una de las escasas referencias que supera la mera dimensión local o de centro que se puede localizar en la literatura académica, es la investigación de Rué (2005), quien a partir de datos parciales y estudios estimativos señaló lo siguiente: "calculamos entre un 5 y $10 \%$ el porcentaje de alumnos en edad escolar afectados por el fenómeno del absentismo, entre leve y crónico, en el área Metropolitana de Barcelona" (pp. 62-63). 
Otras referencias globales de interés que inciden en subrayar una presencia destacada de absentismo se pueden localizar en los informes PISA. El de 2012 indica al respecto: "Más del 28\% de los alumnos españoles señaló haber faltado al menos un (sic) (24\% uno o dos días; $3 \%$ tres o cuatro días y $1 \%$ más de cinco días)" ${ }^{\prime \prime}$ Y añade que España se encuentra dentro del grupo de países de la OCDE y de la UE con mayor porcentaje de alumnos que dicen haber faltado a clase, ya que el promedio entre los países estudiados es del $15 \%$, refiriéndose en todos los casos a faltas injustificadas. (Ministerio de Educación, 2014, p. 139).

Esta interesante referencia no tiene continuidad en el informe preliminar de los resultados del estudio realizado en 2015, en el cual no aparece ninguna información al respecto. (Ministerio de Educación, 2016). En cambio, en un breve resumen, la OCDE indica que la situación de absentismo en nuestro sistema educativo continúa por encima de la media de los países miembros de esa organización. Esta se sitúa entre el $19 \%$ y el $20 \%$ y la española se ha reducido tres puntos desde la anterior medición, quedando en el 25\%. (OCDE, 2016, p. 12)

Aunque la tendencia sea hacia reducción, pensamos que se trata de cifras muy abultadas, teniendo en cuenta de que el estudio de 2015, en concreto, se llevó a cabo sobre una amplia muestra de 37.205 alumnos, matriculados en $4^{\circ}$ de la ESO y repartidos en 980 centros educativos. Si proyectamos esas cifras al conjunto del sistema educativo, supondría que esa situación de absentismo se daría en uno de cada cuatro alumnos que estén cursando $4^{\circ}$ de secundaria obligatoria en nuestro país.

Pese a la magnitud de las cifras que estamos manejando y a que el estudio de Rué, fue distinguido con un premio nacional de investigación educativa, desde esta fecha apenas se han realizado avances para acotar cuantitativamente tan destacado problema. Es más, el adelanto publicado de Datos y cifras Curso escolar 2019/2020, sí que incluye amplias referencias al abandono escolar temprano, mientras no se puede localizar ni una sola sobre el incumplimiento al derecho a la educación que supone el absentismo. (Ministerio de Educación, 2019)

Otras interesantes referencias cuantitativas, aunque referidas a un ámbito territorial más reducido, las encontramos en la Memòria anual sobre la convivència escolar en la Comunitat Valencian. Curs 2017-18, publicado por la Conselleria de Educació, Investigació, Cultura y Esport. El documento señala que los centros educativos valencianos remitieron durante ese curso 6.851 expedientes de menores absentistas a los servicios municipales de los municipios en los que se encuentran ubicados (p. 61).

Creemos que las cifras del citado informe deben mover a la reflexión, ya que casi 6.900 estudiantes valencianos han visto seriamente incumplido su derecho a la educación. Pero es que, además, con ser una cantidad elevada, la cifra resulta bastante superior a la contabilizada el curso anterior, en el cual se identificaron 5.937 casos (Consellería d'Educació, 2018, 48). Esto es, de un curso a otro se remitieron 914 expedientes más a los correspondientes servicios municipales, lo que supone un incremento porcentual del 15,39\%. 
Pero no es ese el único elemento preocupante. Según se señala en el informe, de todas las conductas contrarias a la correcta convivencia recogidas en el mismo - diversas modalidades de acoso, agresiones, violencia, vandalismo, consumo de drogas, etc.-, la absentista fue la que acumuló mayor número de incidencias. Además, debe tenerse en cuenta que esos estudiantes son aquellos que los centros, tras haber realizado una primera fase de intervenciones con sus propios recursos, no han conseguido reconducir. Esas actuaciones iniciales no se encuentran reflejadas en el documento, por lo que se desconoce su número. Igualmente, se debe tener en cuenta que de las 2.077 entidades educativas existentes en la Comunitat Valenciana, la memoria incluye referencias de 1.796, algo más del 86\%. Por tanto, el cómputo final de estudiantes absentistas en la Comunitat Valenciana superar necesariamente los 6.851, sin qué, debido a las ya señaladas limitaciones, pueda concretarse en una cifra precisa.

También debemos tener en cuenta que, tal como se indica en la Memoria que estamos siguiendo, de todas las incidencias recogidas, la ausencia injustificada a clase fue la que presentó el porcentaje de más bajo resolución efectiva. Solo el $44,92 \%$ de los casos concluyeron con la reincorporación de los estudiantes afectados a las aulas. Porcentaje sensiblemente inferior, por ejemplo, al presentado por los comportamientos relacionados con cualquier tipo de acoso -por orientación sexual, género, racial, etc.- consumo y tráfico de drogas, agresiones o vandalismo, todas las cuales tienen un porcentaje de resolución efectiva situado entre el 95 y el $76 \%$. Para el absentismo, tal indicador no solo se queda en el $44,92 \%$, si no que esa cifra es, además, 3,69 puntos menor que la consignada en el curso anterior.

Podemos completar el panorama del absentismo en la Comunitat Valenciana con la mirada que aporta un reciente estudio sobre la intervención durante el curso 201617 de los servicios de bienestar social de 39 corporaciones locales de ese territorio que cuentan con un censo superior a los 25.000 habitantes (Cruz y Horcas, 2019). Entre todas suman un censo conjunto de 3.033.905 personas, lo que representa el $61,4 \%$ de la población total de la Comunitat Valenciana. Perfilando algo más las cifras, en el conjunto de esas localidades residen 326.930 jóvenes de entre los 6 y 16 años, lo cual supone el $57,3 \%$ de la población en edad de escolarización obligatoria de todo ese territorio.

De esa población escolar se ha procedido a cuantificar en números absolutos el alumnado absentista de cada una de las localidades. Teniendo en cuenta esas cifras, observamos la existencia de un importante rango de dispersión. En un extremo se sitúan cerca de una decena con muy pocos casos. En ninguno de ellos se llegaron a contabilizar la treintena de expedientes. En el otro extremo se contabilizan 23 municipios que en el curso 2016-17 realizaron más de 50 intervenciones. En su conjunto, los servicios municipales de estas localidades atendieron a 5.349 estudiantes, el $92,5 \%$ del total. Analizando las cifras más pormenorizadamente, comprobamos que, tal como muestra la Tabla 1, en 15 municipios se realizaron intervenciones en más de 100 estudiantes, en 9 en más de 200, en 5 más de 300, en 4 más de 400, en 2 más de 800 y en 1 más de 900 casos. 
Tabla 1. Municipios de la Comunidad Valenciana con mayores casos de absentismo escolar

\begin{tabular}{|c|c|}
\hline Municipios & Casos de absentismo \\
\hline 23 & +50 \\
\hline 16 & +100 \\
\hline 9 & +200 \\
\hline 5 & +300 \\
\hline 4 & +400 \\
\hline 2 & +800 \\
\hline 1 & +900 \\
\hline
\end{tabular}

Fuente elaboración propia

Esas cifras nos proporcionan una panorámica que nos indica con mucha claridad que en determinadas poblaciones, entre la quincena y la veintena, los centros educativos y las corporaciones locales deben hacer frente a un importante volumen de trabajo relacionado con el absentismo, al que deben destinar una significativa cantidad de recursos.

Para perfilar con mayor precisión la incidencia, se ha calculado las tasas porcentuales de absentismo municipio a municipio, dividiendo en cada caso el número de expedientes por la población escolar. El rango de dispersión por localidad se sitúa entre el $0,08 \%$ hasta el 4,93\%. Más concretamente, se localizan tres poblaciones con tasas superiores al 4\%, otras seis con porcentajes entre el 3 y 3,99\%, igual número con tasas entre el 2 y el 2,99\%, 11 se sitúan entre 1 y 1,99\% y 13 municipios presentan una tasa de absentismo por debajo del $1 \%$.

No queremos finalizar este apartado sin plantear, si quiera esquemáticamente, otra faceta del absentismo que complementa lo analizado hasta el momento. Nos referimos al alumnado que asiste con regularidad al centro y a las clases pero que presenta un comportamiento de total pasividad. Son situaciones que se producen por actitudes de desafección escolar y de rechazo hacia los procesos de enseñanza aprendizaje por razones diversas, entre las que se pueden identificar: experiencias escolares negativas previas; dificultades de aprendizaje; problemas de salud; complicaciones afectivas; relaciones negativas con el profesorado, etc. (González, 2014; García Gracia y Razeto, 2019). En este sentido, los alumnos que se ausentan de las aulas debe ser considerados absentistas, pero algunos otros que acuden regularmente a clase también desarrollan conductas de desconexión académica, por lo que en ambos casos se dan importantes déficits en los procesos de enseñanza y aprendizaje.

\section{CONCLUSIONES Y DISCUSIÓN}

La primera conclusión resulta evidente: el absentismo escolar supone un problema de entidad para la política educativa española. Pese a su relativa invisibilidad, 
académica, social y educativa, aunque apenas se pueden localizar datos y estudios amplios y pormenorizados, las referencias existentes, tanto sobre el sistema educativo del territorio nacional en su conjunto, como en el más concreto de la Comunidad Valenciana, nos permiten afirmar que existe un número significativo de alumnos y alumnas en edad de escolarización obligatoria que desarrollan conductas absentistas.

La citada ausencia de trabajos sobre muestras numerosas y con series cronológicas amplias, nos impide concretar el problema en una cifra precisa. Pero los datos manejados procedentes de estudios académicos, informes PISA, investigaciones sociales y educativas, nos permiten afirmar que el absentismo escolar hoy en día en nuestro país afecta a miles de chicos y chicas, los cuales ven menoscabado, en algunos casos muy seriamente, el derecho a la educación, derecho, recordemos, reiteradamente señalado en la legislación educativa, de protección al menor y consagrado por la Constitución actualmente en vigor.

De acuerdo con lo anterior, nos encontramos ante un panorama y unos planteamientos bastante claros, pero ciertamente peculiares. Por un lado, un amplio consenso social y político concretado en una definición claramente proactiva del derecho a la educación y de la escolarización obligatoria, la cual, además, se encuentra especialmente perfilada en la normativa, estatal y autonómica, de protección del menor, y cuyo incumplimiento está contemplado, en última instancia y de acuerdo con determinadas circunstancias, hasta en el código penal. $Y$ junto a ello una realidad de absentismo en un sector del alumnado, difusa, desigualmente repartida, escasamente cuantificada y con menguada presencia pública, pero que ocupa significativos recursos educativos, de los servicios sociales y de la administración de justicia. Una situación que, en nuestra opinión, requiere una atención más intensa por parte de los responsables políticos, ya que, volvemos a insistir, según nuestro ordenamiento jurídico, el derecho a la educación en nuestro país presenta la consideración de derecho fundamental.

Desde una perspectiva más técnica, nos gustaría señalar otro aspecto relevante. Como se ha señalado en páginas anteriores, el tratamiento del alumnado con comportamiento absentista supone un proceso complejo. Al tratarse la escolarización de una competencia compartida, intervienen diversas entidades de ámbitos muy diversos -educativo, bienestar social y judicial-, con normativas, metodologías y culturas de trabajo sensiblemente, diferentes Por ello, estamos convencidos que resultaría de gran importancia y de indudable eficacia, incrementar sensiblemente la coordinación institucional, por lo que sería de utilidad que todo el personal técnico que interviene en esos procedimientos, tuviera una visión global de los mismos, en especial en lo referente a las funciones, competencias, recursos y protocolos de intervención del resto de entidades.

Sobre ese particular, debe realizarse especial hincapié en que, de acuerdo con lo previsto en la normativa actualmente vigente, las actuaciones de la Fiscalía de Menores, deben considerarse como un último recurso. Recordemos que su trabajo consiste en averiguar si existe base suficiente para una posible acusación contra los padres en el marco de lo dispuesto en el código penal. Resulta evidente que se trata de un ámbito bastante inadecuado en lo que respecta a la recuperación de la asistencia de 
alumnos y alumnas a las aulas. El problema de las ausencias injustificadas a clase es un problema esencialmente educativo y social, y en esos ámbitos es donde debe tratarse e intentar encontrar soluciones. Lo tribunales de justicia solo deben ocuparse de las contadas situaciones en que se considere castigar penalmente los comportamientos paternos.

Por último, debemos indicar que si bien, tradicionalmente, se ha asociado el absentismo a las circunstancias sociales, económicas y personales de los menores, exonerando a los centros educativos de su responsabilidad, actualmente una buena parte de los estudios más completos sobre este problema tienen muy en cuenta la influencia del contexto escolar y del sistema educativo, en el abandono de la asistencia a las aulas de los alumnos y alumnas. Completando esta reflexión con algunas de las anteriores, sería muy deseable que los centros educativos incrementaran sus intervenciones en todo lo relacionado con el alumnado en edad de escolarización obligatoria que se ausenta injustificadamente de las aulas. Incluso sería especialmente oportuno que se diseñaran, llegado el caso, programas de prevención en colaboración de los servicios de bienestar social.

El absentismo escolar es un serio problema, que en bastantes ocasiones provoca consecuencias muy negativas en los alumnos y las alumnas que desarrollan ese tipo de conductas. Supone un incumplimiento del derecho a la educación y por ello debería ser objeto de una mayor y mejor atención por parte de las autoridades, que potenciara una intervención más amplia, pormenorizada y eficaz.

\section{REFERENCIAS BIBLIOGRÁFICAS}

Asamblea General de la ONU (1948). "Declaración Universal de los Derechos Humanos". Recuperado de https://www.un.org/es/universal-declaration-human-rights/

Asensio, I., Carpintero, E., Expósito, E. y López Martín, E. (2018). ¿Cuánto oro hay entre la arena? Minería de datos con los resultados de España en PISA 2015. Revista Española de Pedagogía, 76(270), 225-245. https://doi.org/10.22550/REP762-2018-02.

Bueno, V. (2005). Absentismo escolar y educación social. Políticas desarrolladas en la Comunidad Valenciana en torno al absentismo escolar. Indivisa: Boletín de estudios e investigación, 6, 261-277.

Calero, J., Choi, Á. y Waisgrais, S. (2010). Determinantes del riesgo de fracaso escolar en España: una aproximación a través de un análisis multinivel aplicado a PISA 2006. Revista de Educación, número extraordinario, 225-256.

Comunidad Valenciana. Ley 26/2018, de 21 de diciembre, de la Generalitat, de derechos y garantías de la Infancia y la adolescencia. Diario Oficial de la Generalitat de 24 de diciembre de 2018, núm. 8450. Recuperado de https://www.dogv.gva. es/portal/ficha_disposicion_pc.jsp?sig=011597/2018\&L=1

Consellería de Educació, Investigació, Cultura i Esport (2018). Memòria anual sobre la convivència escolar en la Comunitat Valenciana Curs 2016-2017. Recuperado 
de http://www.ceice.gva.es/documents/162793785/163278742/Pu_180925_Memoria_cvescolar_2016_2017.pdf/75cc3a18-9fc0-4566-aec2-1a08e2a06713

Consellería de Educació, Investigació, Cultura i Esport (2019). Memòria anual sobre la convivència escolar en la Comunitat Valenciana Curs 2017-2018. Recuperado de http://www.ceice.gva.es/documents/162793785/163278742/Mem\%C3\%B2ri a+de+conviv\%C3\%A8ncia+escolar_2017_2018.pdf/e48ce4ea-c662-4067-a96ad5b1f8ef897d

Constitución Española. Boletín Oficial del Estado, 29 de diciembre de 1978, núm. 311.

Cruz, J. I. (2019). La gran zozobra roja. Argumentos para la extensión de la Enseñanza Media en España (1953-1961). Revista Complutense de Educación, 30(4), 983996. https://doi.org/10.5209/rced.59882.

Cruz, J. I., García, S. y Grau, R. (2016). Derecho a la educación y absentismo escolar en España: Perspectiva normativa. En M. Nogueira Diógenes, M. G. Correia Gomes, y W. C. Monteiro da Silva (Eds.), Políticas públicas de educação: olhares transversais (pp. 59-73). Curitiba, Brasil: Editorial CRV.

Cruz, J. I., García, S. y Grau, R. (2017). Adolescentes en situación de reiterado absentismo escolar. Un estudio a partir de las diligencias de investigación penal de la Fiscalía de Valencia. Profesorado. Revista de curriculum y formación del profesorado, 21(4), 159-175.

Cruz J. I. y Horcas, V. (2019). Absentismo escolar e intervención municipal. Un análisis de la Comunitat Valenciana. En J. I. Cruz, S. García. Derecho a la educación y absentismo escolar. Valencia: Tirant, (en prensa).

Escudero Muñoz, J. y Rodríguez Entrena, M. (2011). Afinar la comprensión y movilizar políticas consecuentes para afrontar el abandono escolar temprano. Avances en Supervisión Educativa, 14, 1-15.

Escudero, J. M. y Martínez, B. (2012). Las políticas de lucha contra el fracaso escolar: ¿programas especiales o cambios profundos del sistema y la educación? Revista de Educación, número extraordinario, 174-193.

Faci, F. (2011). El abandono escolar prematuro en España. Avances en supervisión educativa, Revista de la Asociación de Directores de Educación de España, 14, $1-26$.

García Gracia, M. (2013). Absentismo y abandono escolar. Madrid: Síntesis.

García Gracia, M. y Razeto, A. (2019). ¿Por qué faltan los jóvenes a la escuela? Una explotación de la experiencia escolar del alumnado absentista en Cataluña. Perfiles Educativos, 165, 43-61. https://doi.org/10.22201/ iisue.24486167e.2019.165.59015.

González, Ma . T. (2006). Absentismo y abandono escolar: una situación singular de la exclusión educativa. REICE. Revista Iberoamericana sobre Calidad, Eficacia y Cambio en Educación, 4(1), 1-15. 
González, Ma . T. (2014). Absentismo escolar: posibles respuestas desde el centro educativo. REICE. Revista Iberoamericana sobre Calidad, Eficacia y Cambio en Educación, 12(2), 5-27.

Ley Orgánica 10/1995, de 23 de noviembre, del Código Penal. Boletín Oficial del Estado de 29 de julio de 2015, núm. 180.

Ley Orgánica 1/1996, de 15 de enero, de Protección Jurídica del Menor, de modificación parcial del Código Civil y de la Ley de Enjuiciamiento Civil. Boletín Oficial del Estado de 17 de enero de 1996, núm. 15.

Ley Orgánica 8/2013, de 9 de diciembre, para la mejora de la calidad educativa. Boletín Oficial del Estado de 10 de diciembre de 2013, núm. 295.

Ley 27/2013, de 27 de diciembre, de racionalización y sostenibilidad de la Administración Local. Boletín Oficial del Estado de 30 de diciembre de 2013, núm. 312.

Ley 26/2015, de 28 de julio, de modificación del sistema de protección a la infancia y a la adolescencia. Boletín Oficial del Estado de 29 de julio de 2015, núm. 180.

Ministerio de Educación, Cultura y Deporte (2014). Pisa 2012 programa para la evaluación internacional de los alumnos Informe español. Resultados y contexto. Recuperado de https:/www.educacionyfp.gob.es/inee/dam/jcr:d5e1e2e2-37bd4619-a68f-346ed8132b04/pisa2012.pdf

Ministerio de Educación, Cultura y Deporte (2016). PISA 2015 Programa para la EvaIuación Internacional de los Alumnos Informe Español. Madrid: Instituto Nacional de Evaluación Educativa. Recuperado de https://www.educacionyfp.gob.es/inee/ dam/jcr:e4224d22-f7ac-41ff-a0cf-876ee5d9114f/pisa2015preliminarok.pdf

Ministerio de Educación y Formación Profesional (2019). Datos y cifras del curso 2019/2020. Madrid, España: Secretaría General Técnica. Recuperado de http:// www.educacionyfp.gob.es/dam/jcr:b998eea2-76c0-4466-946e-965698e9498d/ datosycifras1920esp.pdf

OCDE. (2016). Pisa 2015 resultados clave. OCDE. Recuperado de http://www.oecd. org/pisa/pisa-2015-results-in-focus-ESP.pdf

Portela Ruaño, A., Nieto Cano, J. M. y Torres Soto, A. (2019). La reincorporación formativa de jóvenes que abandonan tempranamente la educación; relevancia de su trayectoria previa. Revista Española de Pedagogía, 272, 103-121.

Rodríguez-Mantilla J. M, Fernández-Díaz Ma. J. y Jover G. (2018). PISA 2015: Predictores del rendimiento en Ciencias en España. Revista de Educación, 380, 75-102. https://doi.org/10.4438/1988-592X-RE-2017-380-373.

Rué, J. (2005). El absentismo escolar como reto para la calidad educativa. Madrid: Centro de Investigación y Documentación Educativa.

Viñao, A. (2004). Escuela para todos. Educación y modernidad en la España del siglo XX. Madrid: Marcial Pons. 